Levin, B., \& Matthews, C. (1997). Using Hypermedia to Educate Preservice Teachers about Gender Equity Issues in Elementary School Classrooms. The Journal of Research on Technology in Education, $29(3), 226-247$.

Made available courtesy of International Society for Technology in Education.

\title{
Using Hypermedia to Educate Preservice Teachers About Gender-Equity Issues in Elementary School Classrooms
}

\author{
Barbara B. Levin and Catherine E. Matthews \\ University of North Carolina at Greensboro
}

\begin{abstract}
This study highlights what preservice teachers learned from interacting with a HyperStudio stack about gender-equity issues. Teachers gained background information from the stack and then used this knowledge to resolve inequities presented in various interactive scenarios. Qualitative and quantitative evidence shows how interaction with this stack positively affected preservice teachers' interests in, attitudes about, and awareness and knowledge of genderequity issues. By confronting gender issues in a hypermedia environment that details inequities in classroom interaction patterns, language, role models, gender expectations, and curriculum, preservice teachers will be better prepared to face these issues in their elementary school classrooms. (Keywords: elementary education, equity, gender, hypermedia, multimedia, teacher training.)
\end{abstract}

The premise of this study is that preservice teachers can benefit from learning about gender-equity issues in a hypermedia environment. This article highlights what 51 preservice teachers, college juniors and seniors, learned from interacting with a hypermedia stack about gender equity. Both quantitative and qualitative data on the impact of this intervention are presented. We predicted that preservice teachers' level of awareness, knowledge of gender-equity issues, and attitudes about and interest in gender issues would increase as a result of their interaction with this hypermedia program. We report our findings in this article.

\section{GENDER EQUITY CONCERNS}

Gender inequities in the fields of math, science, and technology are well documented and the statistics are shocking. The 1992 monograph How Schools Shortchange Girls by the American Association of University Women (AAUW), provides ample evidence of some of the gender inequities that persist today: Although women comprise $45 \%$ of the work force, they hold jobs concentrated in clerical, service, and professional fields such as teaching and nursing rather than in mathematics, science, or engineering. Women with similar educational backgrounds and experiences as men earn only 66 cents for every dollar men

The HyperStudio stack described in this article is available from the authors on Macintosh CD-ROM. The CD-ROM also contains a version of the program designed for third-through sixth-grade students. 
earn, although this wage gap is slowly decreasing. Although girls start kindergarten with higher achievement levels than boys, 12 years later they score lower on such tests as the PSAT, SAT, and ACT. As a result, girls receive only $36 \%$ of the National Merit Scholarships, and they are less likely to complete higher level math, science, and technology courses (AAUW, 1992; Sadker \& Sadker, 1985; Sadker, Sadker, \& Steindam, 1989). For example, only $16 \%$ of engineering graduates in 1993 were female (Zachary, 1994). Even in education, a "woman's" profession, men rise to the top positions in schools. Although $72 \%$ of elementary and secondary teachers are women, only $28 \%$ of principals and $5 \%$ of school superintendents are females (AAUW, 1992).

These inequities affect females' self-esteem, self-concepts, participation, and achievement patterns in science and mathematics. For example, although $60 \%$ of girls and $67 \%$ of boys in elementary grades claim to be happy the way they are, only $29 \%$ of high school girls report being happy with themselves (AAUW, 1992). Furthermore, the sharpest decline in self-esteem for girls occurs between the elementary and middle school years (AAUW, 1992). Girls are much more likely than boys to say that they are not smart enough to pursue careers that require higher level math, science, or technology skills. As a result, self-esteem and self-perceptions about career possibilities are lower for girls than for boys.

The AAUW monograph also reports that girls' feelings about their academic performance correlates highly with their relationships with teachers. Teachers are important role models for young women and affect the self-esteem of girls in their classes. They also influence their interests and aspirations. Therefore, teachers and teacher educators need to be made aware of gender-equity issues in the classroom so that they can encourage both girls and boys to take an interest in math, science, and technology. Unfortunately, teacher education programs have inadequately prepared teachers to address gender-equity issues. Among the reasons for this are (a) a lack of information about the available research in this field and (b) a paucity of successful interventions (Rose \& Dunne, 1989). This article attempts to fill this gap by providing teacher educators with information and strategies that they can use with their preservice students to address gender inequities in elementary schools.

A hypermedia presentation was developed around five content themes (classroom interactions, language, role models, gender expectations, and curriculum) and five interaction categories (initial responses, background information, more responses, strategies, and scenarios). A 5 x 5 grid (or map) was thus created for teachers to explore in any order they choose to learn more about the issue of gender equity in elementary school classrooms. Figure 1 shows the organizational card from the stack. The program is designed to provide teachers with knowledge and strategies to address gender-equity issues in the classroom.

\section{Rationale for Using a Hypermedia Environment}

For the purposes of this study, we define "hypermedia" as a computer-based system that allows nonsequential access to video, text, graphics, images, and audio, using interactive links that create flexible, interactive learning environments. 


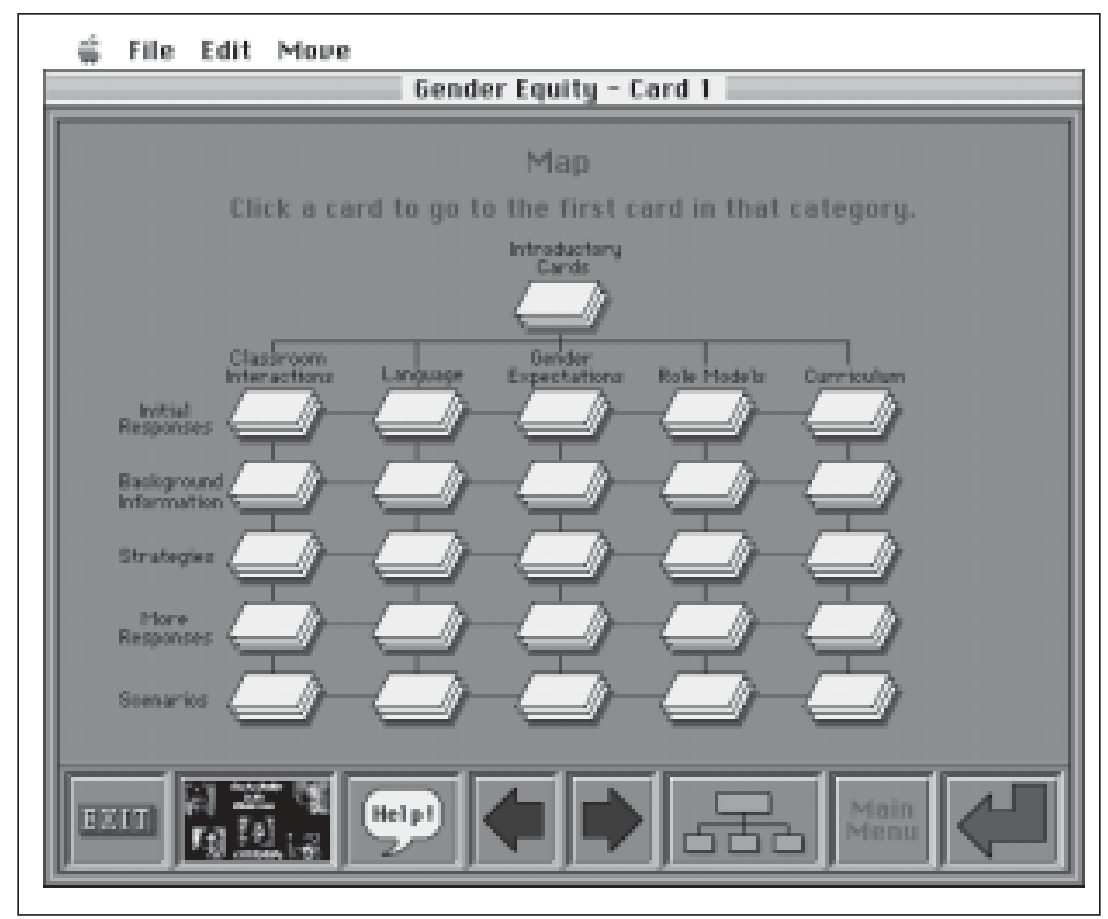

Figure 1. "Map" card in gender equity stack, showing the structure of the stack based on the five themes and five interaction categories used to create it

In this research we used a limited hypermedia tool, one that not only permitted, but required, encounters with multiple cases, but that did not allow nonlinear traversal of the program. We contend that even such a limited hypermedia program can serve as an effective pedagogical tool for learning about complex issues such as gender equity because the use of this knowledge is case centered rather than knowledge centered (Spiro \& Jehng, 1990; Jacobson \& Spiro, 1995). Understanding gender-equity issues in the classroom requires situated learning that is case based, rather than the simple presentation of abstract descriptions of the issues involved (Bransford, Sherwood, Haselbring, Kinzer, \& Williams, 1990). Spiro and his colleagues (Spiro \& Jehng, 1990; Jacobson \& Spiro, 1995) argue that when a domain is ill structured and complex, as this one certainly is, a good way to enhance learning in that domain is to use multiple cases and examples, so that learners can come to understand the ill-structured concepts and flexibly apply them by experiencing them in different cases or contexts.

Although we understand that the medium is not necessarily the message (Clark, 1983, 1985, 1994), we do know from cognitive science research that certain types of learning can be enhanced through exposure to hypermedia learning situations (Bransford et al., 1990; Kozma, 1991; Spiro \& Jehng, 1990; Jacobson \& Spiro, 1995). For example, hypermedia is considered to be an ap- 
propriate delivery system when the learning and its application and transfer are situation and context dependent (Jacobson \& Spiro, 1995; Spiro \& Jehng, 1990). Theoretically, learning material that is represented in multiple ways, such as video, text, audio, and graphics (Bransford et al., 1990; Jacobson \& Spiro, 1995; Spiro \& Jehng, 1990), allows users to better transfer learning to new situations and apply newly acquired knowledge.

Learning about gender-equity issues by simply reading or hearing about them in single, simple, or abstract presentations is not the same as seeing, thinking about, and reflecting in writing on multiple, specific, and complex examples. Multiple examples are important for building an understanding of the complexity and subtlety of gender-equity issues in classrooms. Furthermore, these examples must be embedded in real cases that teachers can relate to and recognize. Knowing what to do or say depends on the situation or the case in point; knowing why is also contextual. Both verisimilitude and multiple case examples are required to bridge the gap from hypothetical or theoretical to real understanding if learning is to occur and any changes in behaviors are to be made regarding gender equity in classrooms. Therefore we used a hypermedia environment based on these learning principles to educate preservice teachers about gender issues in elementary math, science, and technology classrooms.

\section{BACKGROUND ON GENDER EQUITY}

Until the 1970s, research on gender differences in schools focused on the poor performance and behaviors of male students, specifically males' lower reading proficiencies and lower report card grades (Sadker, Sadker, \& Klein, 1991). Despite these gender differences, the research of Frazier and Sadker (1973) revealed that classroom interaction patterns between teachers and students subtly favored their male students to the detriment of their female students. The conclusion of this line of research was that girls and minorities are usually shortchanged when it comes to the critical currency of classroom interaction among students and teachers (Sadker et al., 1989).

In a meta-analysis of classroom interaction patterns, Kelly (as cited in Sadker et al., 1991) estimated that teachers interact more with male students $(56 \%)$ than with female students (44\%). Studies of student-teacher classroom interactions patterns show that teachers: (a) call on boys more often than girls; (b) accept boys' called-out answers more than girls'; (c) tell girls who call out answers to raise their hands (boys are more than eight times as likely to call out answers as girls); (d) wait longer for boys' answers; (e) ask boys interpretative, higher level questions while asking girls factual, lower level questions; (f) give girls neutral responses while giving boys complex responses; and (g) allow boys more time to talk. In addition, girls receive praise for the appearance of their work, while boys receive praise for the content of their work. Teachers tell boys how to solve problems and often solve problems for girls. Teachers also discipline boys more often than they discipline girls, even when they misbehave equally. Boys receive more criticism and more corrective feedback concerning behavior than do girls. Teachers circulate more among boys' desks and position them- 
selves more toward boys than girls. In short, girls are shortchanged in school when it comes to their interactions with teachers (Sadker et al., 1989).

Unfortunately, these inequities are also reinforced through language, role models, gender expectations, and the content of the curriculum. According to Sadker and Sadker (1994), when careers are described using male pronouns, females find the job less appealing than when neutral terms are used. For example, when "man" is said, man is seen in the mind's eye. Although the results of authors' and publishers' recent efforts to rectify centuries of bias in textbooks is seen with increasing frequency as chapters or boxes that are labeled "Famous Women Scientists," students are still left with a fragmented world view that males are the main story and women are a sideshow, confined to a brief insert, anecdote, or biographical summary. Textbooks continue to represent the authority of the printed word and in many educational materials used by elementary school children, females are usually depicted stereotypically. Yet, studies have shown that girls who meet scientists and watch them at work are more likely to consider becoming scientists. Unfortunately, gender expectations are often biased. When girls bring home low grades in math and science, parents say that their daughters are not as smart in these subjects. When boys bring home similar grades, parents say their sons are lazy and push them to work harder.

Despite this litany of gender-biased conditions in elementary school classrooms, most teachers deny that they or their colleagues are inequitable in their teaching with regard to gender (Sadker \& Sadker, 1985). In fact, teachers are quite surprised when these gender-based inequities are pointed out (Failing at Fairness, 1992). But brief, focused training can serve to reduce or eliminate gender bias from classrooms according to Sadker and Sadker (1986). However, no empirical studies of gender-equity issues using hypermedia learning environments have been reported to date. Furthermore, those studies based on a single medium, such as teachers' reactions to videotaped examples of gender bias in classrooms, indicate that most teachers fail to recognize subtle and notso-subtle gender inequities in their own or other people's classrooms (Failing at Fairness, 1992; Sadker \& Sadker, 1985). Therefore, when designing this study we asked ourselves: Can an interactive hypermedia presentation on genderequity issues in the elementary school classroom provide such training? Our main research question is: What is the effect of an interactive hypermedia presentation on the level of awareness, interest, attitudes, and knowledge of preservice teachers about five specific gender-equity issues (classroom interactions, language, role models, gender expectations, and the content of the curriculum) in the elementary school classroom?

\section{Gender Equity Stack Description}

The intervention studied here, in the form of an interactive hypermedia program entitled "Gender Equity in the Elementary School Classroom," was designed to include the following three types of hypermedia utilization (Nelson \& Palumbo, 1992): 
1. Knowledge representation (in multiple forms).

2. Knowledge construction (using writing responses to dilemma-based scenarios).

3. Knowledge presentation (in the form of video, text, graphics, images, and audio).

The hypermedia stack used in this study was designed using HyperStudio 3.0 from Roger Wagner Productions, Inc.

The stack was designed to provide information and strategies and to elicit responses from the users in an interactive format. The target audience was teachers, both preservice and inservice educators. The program runs from a CD-ROM and presents information about and strategies for dealing with five specific gender-equity issues including: (a) classroom interaction patterns, (b) language use, (c) role models, (d) gender expectations, and (e) curriculum. These five areas were identified in the literature and selected from resource materials provided by the Teacher Education Equity Project (Sanders, 1995). They represent major themes and distinct categories of gender-equity issues in classrooms that teachers need to understand.

There are also five interaction categories in the stack designed to reinforce each of the five themes, thus creating a $5 \times 5$ grid (or map) that teachers can explore in any order they choose. These 5 categories include: (a) initial responses, (b) background information, (c) more responses, (d) strategies, and (e) scenarios for each theme. The stack is composed of more than 60 cards, with at least one card for every theme for interaction category. Sample cards from the stack are shown in Figures 2-6.

Multiple levels of interaction with the information about gender-equity issues presented in this stack allow numerous opportunities for users to construct new understandings as they progress through the program. The program is highly interactive and engages users by soliciting their thoughts and ideas in response to many different writing prompts and a variety of quizzes. For example, users can take a multiple-choice or true-false quiz, play a matching game, and read

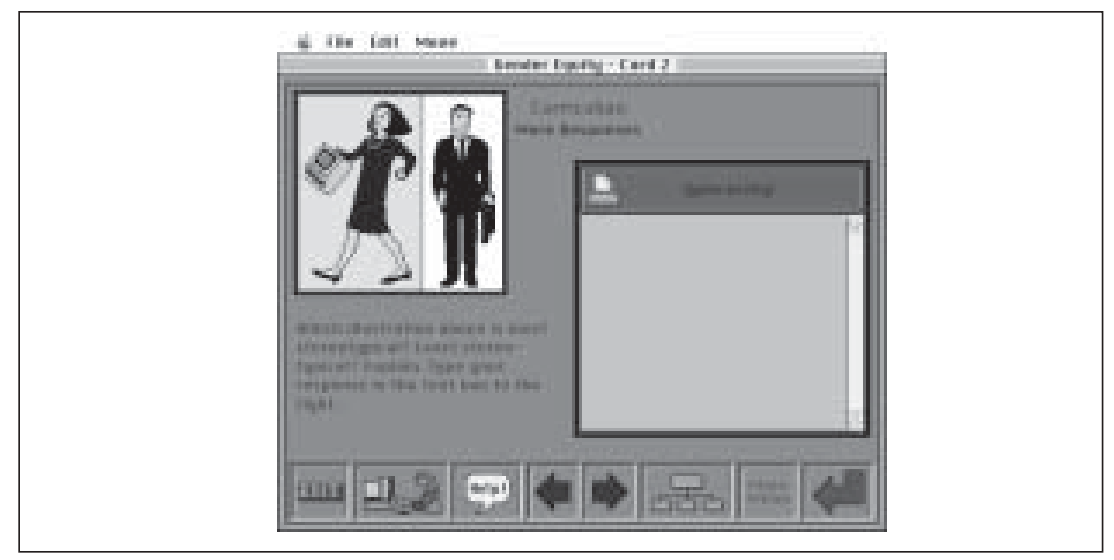

Figure 2. Sample card about curriculum from gender equity stack 


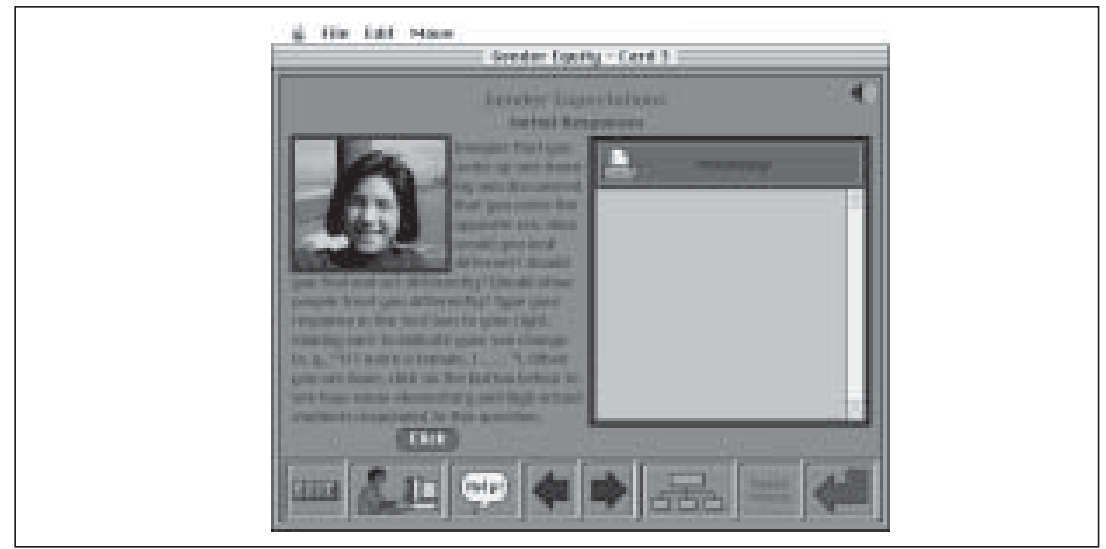

Figure 3. Sample card about gender expectations from gender equity stack

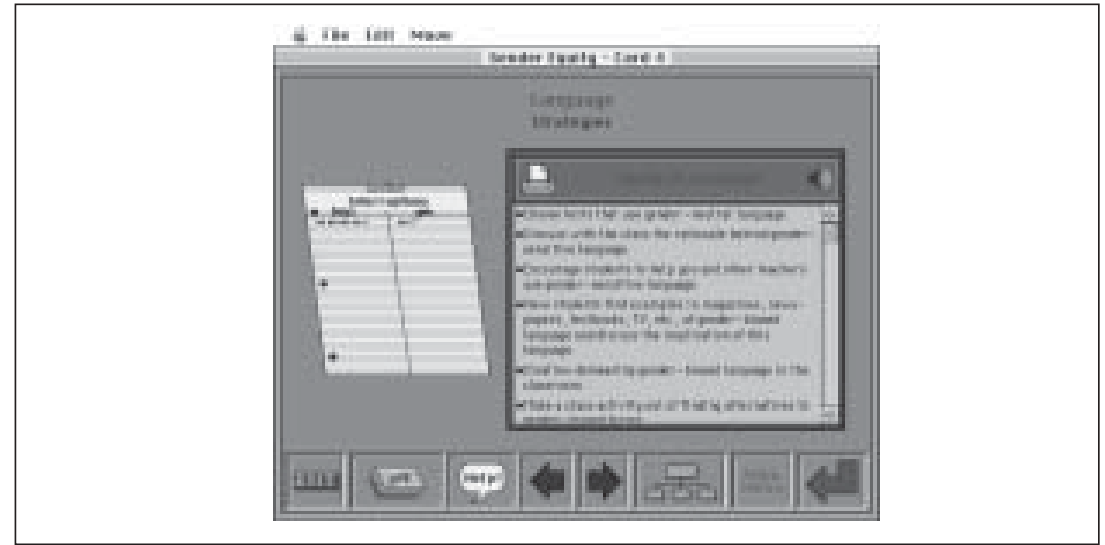

Figure 4. Sample card about language use from gender equity stack

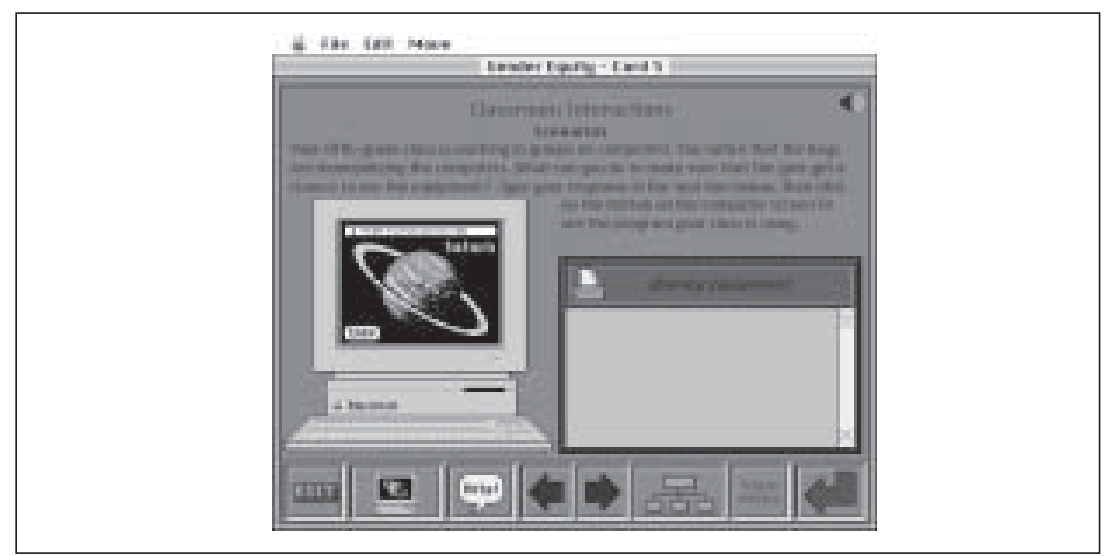

Figure 5. Sample card about classroom interaction from gender equity stack 


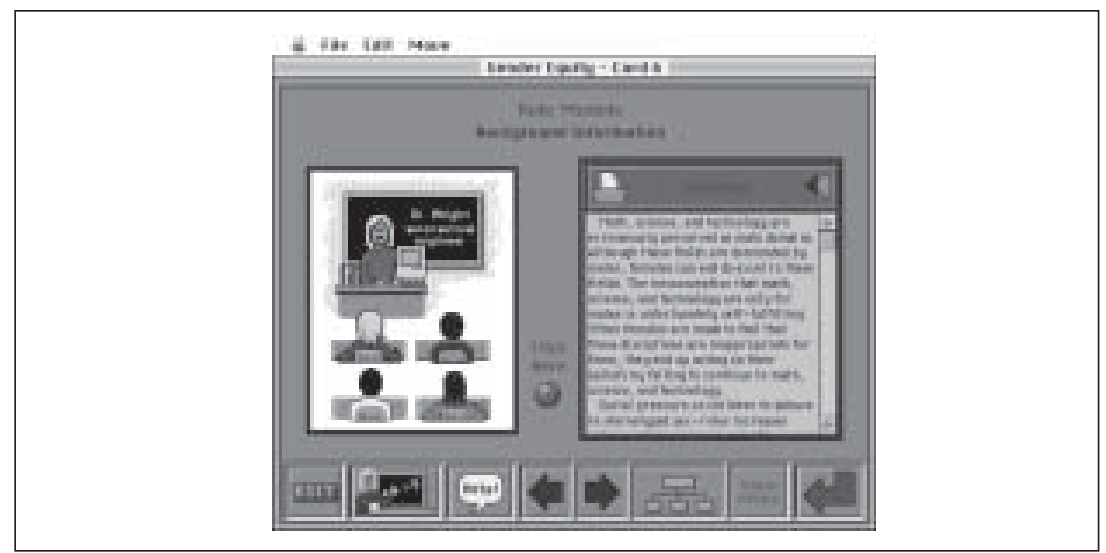

Figure 6. Sample card about role models from gender equity stack

information presented in graphs and charts to answer questions. For additional interaction, classroom scenarios based on real-life examples are presented in vignettes that end with a dilemma or with questions. Some cards also include digitized video and animated cartoons designed to motivate the user and provide additional perspectives. Users are asked to type their responses to 15 different classroom scenarios in scrolling text boxes located next to the scenarios. Users may read what others have written in these text boxes, consider their own and other's points of view, and add their ideas and suggestions to the growing text field. Other special features of the program include the capability of printing all background information and strategies for later reference. In addition, text on most cards can either be read by the user or heard by pressing buttons to activate recordings of the text.

The program is designed for individuals, pairs, or groups to explore. Users may choose to interact with the cards in the stack in any order or in a linear sequence. The program also lends itself to demonstration and discussion with a whole class with an instructor leading the discussion and controlling the order and selection of information to be presented and discussed. However, for the purposes of this study, participants were asked to use the stack linearly, reading one card at a time, and proceeding from the first to the last card so that no cards were missed.

\section{DESIGN OF THE STUDY}

\section{Participants}

Fifty-one preservice students in elementary education ( 24 juniors and 27 seniors) from a teacher education program at a university in the southeast United States participated in this project as a required part of their regular coursework in a weekly seminar. Five students were male; the rest were female. Five participants were students of color; the rest were of European-American ancestry. 
All participants ranged in age from 20 to 30 (with the exception of one 40 year old). Approximately $30 \%$ of the participants were married.

Both junior- and senior-level students participating in this study were involved in two professional development school (PDS) cohort groups, called teams. The authors of this paper served as the junior and senior team leaders. All participants in this study completed pre- and posttests and viewed the gender-equity stack as part of their regular activities in their weekly team seminars. The seniors $(N=27)$ had about $10 \mathrm{hrs}$ of exposure to gender-equity issues prior to this study including a video, required readings, and class discussions. The juniors $(N=24)$ had no systematic exposure to these issues in their teacher education program prior to this study.

\section{Procedures}

The data collection procedures in this study included the following:

1. Completion of a 50-item pretest questionnaire designed to assess levels of awareness of, interest in, attitudes toward, and knowledge of genderequity issues in the classroom. The awareness, interest, and attitude questions were all multiple choice, as were most of the knowledge questions, although a few of these were true or false. Students completed the questionnaire by recording their answers on scan sheets.

2. Completion of a 40-item card-sorting activity designed to assess awareness of key words related to gender-equity issues.

3 . The intervention with the gender equity stack was completed individually in a computer lab in groups of 8 to 10 students during the participants' weekly seminar time. The HyperStudio stack was introduced systematically to the students by the second author using a script. First, all students progressed through the introductory cards in the stack as a group. These cards included the title card; an overview card; a help card; the menu card; and the map card (see Figure 1), which serves as another navigational tool. Second, several features of the stack, such as audio capability, the use of each button on the button ribbon, alternative navigational tools, and the special cartoon buttons, were pointed out. Third, for the purposes of our study, the participants were instructed to complete each card in the stack in a linear fashion, progressing sequentially through each of the five content areas. Because the computer lab was very small and only 8 to 10 students could work on the stack at a time, the researcher and a graduate student were able to observe their progress through the stack and answer individual questions as needed. Although a user can navigate in multiple directions using various tools, the participants in this study were asked to move only by selecting the forward arrow on each card. Thus all students progressed through the stack in the same order, although completion times ranged from 40 to $90 \mathrm{~min}$.

4. Completion of a posttest one week after the hypermedia intervention included a repeat of the pretest questionnaire and the card-sorting activ- 
ity. In addition, written responses to the following two open-ended questions were requested to solicit further feedback about this project:

- How has your thinking about gender equity changed as a result of your interaction with the HyperStudio stack?

- What are some things that you learned from the HyperStudio stack on gender equity that you will use in your classroom teaching experiences?

\section{Content of the Questionnaire}

The 50-item Gender Equity Questionnaire was adapted from a similar but more open-ended instrument (Leach, 1994) and modified for the purposes of this study so that responses could be made using a Likert scale. Six items on the questionnaire inquired about awareness of gender-equity issues. Six more questions asked about students' interests in gender-equity issues. Eight questions probed students' attitudes toward gender-equity issues. The remaining questions focused on assessing students' knowledge of gender-equity issues. The content validity of the questionnaire was supported by the literature in the field.

\section{Quantitative Analysis of Questionnaire and Card-Sorting Activity}

Intact groups of juniors and seniors were selected to participate in this study. Data were not distributed normally; therefore, nonparametric statistical tests were used to analyze the data collected. The Kruskal-Wallis Test (the nonparametric equivalent of ANOVA) was used to test for significant differences between groups (juniors, pretreatment; juniors, posttreatment; seniors, pretreatment; and seniors, posttreatment). If significant differences between groups were identified, either the Wilcoxon Signed-Rank Test for matched pairs (juniors, pretreatment, versus juniors, posttreatment, or seniors, pretreatment, versus seniors, posttreatment) or the Mann-Whitney U-Test for independent samples (juniors, pretreatment, versus seniors, pretreatment, or juniors, posttreatment, versus seniors, posttreatment) was used to further distinguish significant differences.

\section{RESULTS}

\section{Findings from Questionnaire Data}

Analyses of the questionnaire data indicated that even a brief, hour-long exposure to information presented in an interactive hypermedia format about gender-equity issues in the elementary classroom can significantly influence the thinking of preservice teachers. Some interesting group differences were found between the seniors and the juniors who participated in this study. Some differential findings with regard to the awareness, attitudes, interest, and knowledge components of the questionnaire by groups were also identified.

Awareness. As shown in Table 1, a Kruskal-Wallis Test of the four groups (juniors, pretreatment; juniors, posttreatment; seniors, pretreatment; and seniors, posttreatment) indicated significant differences $(p<.001)$ in awareness of gen- 
Table 1

Kruskal-Wallis Test for Awareness of Gender-Equity Issues

\begin{tabular}{lccc}
\hline Group & Count & Sum Ranks & Mean Rank \\
\hline Juniors, pretreatment & 24 & 698.000 & 29.083 \\
Juniors, posttreatment & 23 & 1299.000 & 56.478 \\
Seniors, pretreatment & 27 & 1224.000 & 45.333 \\
Seniors, posttreatment & 24 & 1630.000 & 67.917 \\
\hline
\end{tabular}

Note. Four groups with three degrees of freedom were tested. The Kruskal-Wallis test was significant with a $p<.001$.

der-equity issues. Higher mean-rank scores are indicative of greater awareness. The awareness categories were Very Aware, Aware, Somewhat Aware, and Unaware. A Mann-Whitney U-Test revealed significant differences $(p=.022)$ between the juniors' pretest scores and the seniors' pretest scores, indicating that seniors exhibited a greater level of awareness about gender-equity issues than did the juniors at the beginning of the study.

A Wilcoxon Signed-Rank Test for matched pairs indicated that both the juniors and the seniors made significant gains in awareness of gender-equity issues following their use of the HyperStudio stack. A Mann-Whitney U-Test revealed no significant differences between the posttest scores of the juniors and the seniors with regard to awareness.

There were significant differences between the juniors and seniors on questions from each of the major themes: (a) language, (b) role models, (c) gender expectations, (d) classroom interaction patterns, and (e) curriculum. The mean rank scores in Table 2 indicate that the hypermedia presentation raised the awareness level of the preservice teachers from pretest to posttest for each of the topics in the stack. Higher scores are indicative of greater awareness levels.

Table 2

Mean Ranks for Participant Groups on Specific Awareness Questions

Group Language Role Gender Classroom Curriculum Models Expectations Interaction

$\begin{array}{llllll}\text { Juniors, pretreatment } & 23 & 37 & 30 & 26 & 29 \\ \text { Juniors, posttreatment } & 53 & 57 & 52 & 55 & 61 \\ \text { Seniors, pretreatment } & 56 & 49 & 48 & 49 & 41 \\ \text { Seniors, posttreatment } & 66 & 55 & 68 & 69 & 68\end{array}$

Note. Higher mean-rank scores indicate higher levels of awareness.

Interest. As shown in Table 3, there was no significant difference ( $p=.053)$ between the junior and senior groups of preservice teachers with regard to interest level on the pretest. At the beginning of the study, the seniors were Somewhat Interested in gender-equity issues in the elementary school classroom, 
Table 3

Kruskal-Wallis Test for Interest in Gender-Equity Issues

\begin{tabular}{lcrc}
\hline Group & Count & Sum Ranks & Mean Rank \\
\hline Juniors, pretreatment & 24 & 1241.000 & 51.708 \\
Juniors, posttreatment & 23 & 1332.500 & 57.935 \\
Seniors, pretreatment & 27 & 1002.500 & 37.130 \\
Seniors, posttreatment & 24 & 1275.000 & 53.125 \\
\hline
\end{tabular}

Note. Four groups with three degrees of freedom were tested. The Kruskal-Wallis test was significant with a $p<.053$.

whereas the juniors were Interested in these issues. However, there were significant differences between the seniors' pretest and posttest scores on the Wilcoxon Signed-Rank Test $(p=.018)$ on interest in gender equity, indicating that the seniors increased their level of interest following their interaction with the gender equity hypermedia program. There were no significant differences in posttest results between juniors and seniors.

Attitude. The attitude construct includes a predisposition to act on a particular belief. For example, several of our attitude questions (4 out of 8 ) begin with the statement "I am willing to..." Although there were no significant differences in attitudes toward gender-equity issues among or between groups, students exhibited positive attitudes about gender-equity issues throughout this study as indicated by relatively high scores on these questions, as can be seen in Table 4 .

Table 4

Attitudes Toward Gender-Equity Issues

Attitude Questions

Strongly Agree

Agree

I am willing to monitor my classroom interactions ... $25 \quad 22$

I am willing to vary my instructional technique... $\quad 30 \quad 17$

I am willing to ...find role models... $\quad 25 \quad 22$

I am willing to use ... literature ... $\quad 33 \quad 14$

Boys and girls should receive similar career advice $\quad 38 \quad 9$

Teacher interactions should be similar for boys \& girls $\quad 40 \quad 7$

Knowledge. The last items on the Gender Equity Questionnaire were knowledge items. Selected knowledge items for which there was a significant difference between or among groups were examined more closely. One of the most interesting knowledge questions was the following:

Who is most likely to call out an answer in elementary school without raising a hand?
A. Boys
B. Girls
C. No Difference. 
This is also a question that students were asked to write about in the HyperStudio stack. While interacting with the HyperStudio stack, several students from each group asked if they should answer this question using what they had been told, taught, or read about, or if they should answer based on their personal beliefs. When asked if these two were different, the participants assured the researchers that they were. These incidents, repeated several times in this study, point to the difficulty of merging statistical knowledge with personal knowledge and also to the tenacity with which preservice teachers hold on to their personal beliefs whether or not they are supported by research. When the histograms of pretest and posttest scores for this question were plotted, it became apparent that although many students changed their minds when presented with data contradicting their previous knowledge (59\% of students who selected the incorrect answer on the pretest selected the correct answer on the posttest), many other students $(41 \%)$ did not change their minds about gender equity or classroom interactions.

The question on classroom interaction that asked whether teachers have more and longer interactions with boys or girls elicited similar responses. Although most students agreed with the research findings, some still indicated at the conclusion of the study that there were no differences in classroom interactions patterns between teachers and students based on gender.

Card-Sorting Activity. As a pre- and posttreatment measure of awareness of gender-equity issues, participants were asked to sort a deck of 40 individual cards. Each card contained one key word that related to gender-equity issues. Some examples of the words found on each card include: assertive, outspoken, collaboration, solitary, rational, goal oriented, objective, reticent, empathetic, and process oriented. Students were instructed to sort the cards into two groups-a group that was related to gender-equity issues and a group that was not related to gender-equity issues. A Kruskal-Wallis Test showed significant differences $(p=.0025)$ in scores on the card sort from the pretest to the posttest (see Table 5). Both groups of students initially selected fewer key words related to gender equity before interacting with the HyperStudio stack. After using this program, they selected more keywords relevant to gender-equity issues. Seniors were more aware of terms that related to gender equity on the pretest than were juniors, based on the number of cards selected, but the posttest scores indicated

Table 5

Kruskal-Wallis Test for Card-Sorting Activity Results

\begin{tabular}{lcrc}
\hline Group & Count & Sum Ranks & Mean Ranks \\
\hline Juniors, pretreatment & 24 & 864.500 & 36.021 \\
Juniors, posttreatment & 23 & 1385.500 & 60.239 \\
Seniors, pretreatment & 27 & 1196.500 & 44.315 \\
Seniors, posttreatment & 24 & 1404.500 & 58.521 \\
\hline
\end{tabular}

Note. Four groups with three degrees of freedom were tested. The Kruskal-Wallis test was significant with a $p<.0025$. 
that juniors had become as aware as the seniors following their interaction with the gender equity hypermedia stack.

\section{Findings from Qualitative Analysis of Written Responses}

All participants' written responses entered on the computers during their interaction with the HyperStudio stack were printed, and a content analysis of these responses was conducted. The written responses of the juniors and the seniors were analyzed separately using a constant comparative analysis procedure (Glasser \& Strauss, 1967) to look for patterns and trends in these data (Miles \& Huberman, 1984). The focus of this analysis was on the participants' knowledge of gender-equity issues, rather than on their attitudes, interests, or awareness. Knowledge about each of the five gender-equity themes was investigated. Following this analysis, the written responses of juniors and seniors were compared. Selected responses from both groups were quite similar in content. The differences noted were more representative of pedagogical expertise rather than of understanding of gender issues. That is, the seniors in this study were more experienced with and sophisticated about their understanding of classroom interactions than the juniors, which is not surprising given the seniors' additional year of experience interning in elementary school classrooms.

Classroom Interactions. Participants had four opportunities to write about issues relating to classroom interaction patterns. For example, after being presented information and statistics about the fact that teachers call on boys more than girls, participants were asked why they thought this might be the case. A majority of the participants ( $60 \%$ of the juniors and $78 \%$ of the seniors) indicated in their writing that teachers call on boys more than girls because they perceive that boys are more disruptive and excitable, more likely to call out answers, more aggressive, and less likely to pay attention. In other words, the participants' responses to these questions were related to classroom management concerns. However, $20 \%$ of the juniors wrote that they believe teachers call on boys more because they perceive that boys are smarter than girls, more likely to give the correct answers, and have a greater capacity to succeed in areas such as math and science. Sixteen percent of the juniors wrote that classroom interaction patterns favor boys because of societal beliefs that teachers hold that the education of males is more important than that of females and that male voices are more valued in our society. Interestingly, $23 \%$ of the seniors (and none of the juniors) wrote that teachers do not call on boys more than girls, or, perhaps if they do, it is because there are more boys than girls in the classroom. This finding may be indicative of a stronger socialization in school culture of the seniors, who had more than twice as many hours interning in elementary classrooms as the juniors at the time of this study. Or, perhaps it indicates evidence that even novice teachers deny that they treat boys and girls differently, which Sadker and Sadker (1985) indicate is the case with experienced teachers.

None of the preservice teachers thought that segregating the sexes for instruction was a good solution to providing more equal opportunities for boys and girls to succeed in science and mathematics. Although they could see the shortterm benefits of this potential solution, they felt that this was not a real-world 
situation and that males and females need to learn to work together in school because they will have to do so later in life. The seniors were much better able to articulate reasons on both sides of this issue than the juniors, but all students concluded that any short-term advantages for segregating the sexes were outweighed by long-term negative consequences. One senior wrote:

While segregating by sex will certainly give girls a chance to be more outspoken in certain subjects, I feel that it will prohibit them from learning in real-life situations. You will be living in a world in which males and females work together. The classroom should reflect this. If the teacher takes the time to make sure he/she is teaching in a gender-equitable manner then there should be no need to even consider segregating the class.

In response to a scenario about how teachers might arrange their classroom seating to promote better interaction among boys and girls, $56 \%$ of juniors and $85 \%$ of seniors suggested grouping desks in clusters of four or six in order to promote more cooperative learning. Furthermore, all the seniors suggested mixing equal numbers of males and females in these cluster groups, while the juniors did not address this issue.

Language. Three opportunities for participants to write about issues of language and gender equity were given in the HyperStudio stack. In one scenario, a second-grade boy calls a girl an "airhead" because she can't answer a question and later a boy is called a "sissy" because he brings a teddy bear to school. Nearly all of the participants wrote that these two scenes were similar because they both represented stereotyping by gender. When asked what they would do about this situation, the juniors wrote that they would tell the children they were wrong to say these things and perhaps make the children apologize to each other. The seniors, however, were more pedagogically sophisticated in their responses. They also suggested talking to the students, albeit privately, but said they would take this as an opportunity to introduce and discuss gender equity and fairness. The seniors also wrote more lengthy responses to this scenario than the juniors and expressed explicit concern that this kind of labeling is dangerous to children's self-esteem and cannot be tolerated in the classroom.

In another scenario about gender-sensitive language, all the participants had good suggestions about how they would help children learn to use terms like weather forecaster or meteorologist rather than weatherman. For example, they suggested asking students to view weather reports on television, collect data on the gender of forecasters, or invite a female meteorologist as a guest speaker. Although some of the juniors seemed skeptical about the importance of using gender-free language and thought this issue was one of political correctness rather than gender equity, all of the seniors saw this as an opportunity to educate children about using terms like mail carrier instead of mailman or fire fighter instead of fireman.

Gender Expectations. Participants were asked to write about how they would look, feel, and act if they woke up one morning as a member of the opposite sex. 
This scenario is very revealing and a few found it disconcerting to think about and respond to this writing prompt. The participants' responses were very revealing about how they view the opposite sex and about their own gender expectations.

The females' responses included the following:

I would play and watch more sports and my dad would have played ball with me.

If I were a man I might not be in education. I would get more and better jobs and have a higher salary.

I wouldn't be harassed.

The expectations would be different and I would have more responsibility, more $\$ \$$, and more freedom and independence.

The males responded in the following ways:

I would feel out of place and inferior.

I would try to be outspoken and not allow myself to get pushed around.

I would look better.

I know I would be treated differently.

In response to another scenario about encouraging a female student to join a computer club that is all male, both juniors and seniors had excellent suggestions. Their ideas about how to deal with this situation included the following:

- Suggest that she bring along a friend.

- Talk to her parents.

- Have a guest speaker who is a female scientist.

- Have the class do reports or autobiographies on female scientists.

- Put up pictures of women in these fields.

- Appeal to her leadership strengths.

- Give her a choice, but at least encourage her to try it.

- Ask the boys to suggest ideas to make girls feel more welcome.

Interestingly, many of these strategies could be found in the HyperStudio stack, which is evidence that these preservice teachers were able to apply ideas for nurturing gender equity to new situations if presented with workable strategies. It is also evidence that they were learning from this stack, recalling prior knowledge or experiences, or both.

Role Models. There were also three opportunities to write responses to scenarios about role models. In one of these, the participants were asked to write 
about why they think first graders draw more pictures of female mathematicians than do college students. Most of the participants wrote that first graders drew more women mathematicians because the vast majority of their teachers are female and teach math at school. Therefore, students in first grade associate mathematicians with their female teachers. However, many preservice teachers also wrote that this happens because we learn from society's messages that only men can do math as we grow older. To use their own words:

Children learn their gender roles as they grow up in society. At a first grade level, students are more open-minded and feel free to draw a female mathematician. College students have already fallen into gender roles and tend to draw what they see more often and/or what they think is true.

Young children can see themselves as anything they want to be when they grow up. It is society that places limitations on children. This must mean that school and society need to work on breaking stereotypes so that children really can be anything they want to be.

In another scenario about ways to get fourth-grade girls interested in a unit on space, the participants generated many good strategies. For example, $85 \%$ of the juniors suggested teaching students about women in space by reading about them, doing research on them, or inviting female role models to speak to the class. Their suggestions were concrete and practical, and once again indicated that the preservice teachers using this stack learned from the ideas and strategies presented earlier in the stack and were able to apply newly acquired knowledge and strategies from the hypermedia presentation to new situations as they progressed through the program. The seniors not only offered topicspecific strategies in response to this scenario, but also interpreted this scenario as a generic issue. In so doing, they suggested giving children more choices and allowing them to brainstorm topics to study about any subject, not just space or rockets. This is an interesting developmental difference with regard to pedagogical understanding: The juniors suggested mostly specifics, while many of the seniors could see that the issue of encouraging both boys' and girls' interests is important in all subject areas.

Curriculum. In one of the two scenarios about curriculum, both juniors and seniors wrote that they would create their own word problems and abandon the math textbook if it presented only abstract problems geared to male interests. They also suggested purposefully balancing male and female names in presenting math problems and asking students to make up their own word problems. In the other scenario, they suggested a variety of practical ways to ensure that students were provided with strong female images in the literature they read, including bringing in books from other libraries and visiting the public library if their school library did not have adequate materials. Other suggestions included encouraging reports on female heroines, preparing units about women's accomplishments, and enlisting the help of the school media specialist in or- 
dering more books that highlight women's accomplishments. Once again, the preservice teachers applied strategies presented earlier in the stack to new situations presented later in the stack on the topic of curriculum.

\section{Findings from the Open-Ended Questions}

Each participant responded to the following two open-ended questions as part of the assessment of this hypermedia intervention:

- How has your thinking about gender equity changed as a result of your interaction with the HyperStudio stack?

- What are some things that you learned from the HyperStudio stack on gender equity that you will use in your classroom teaching experiences?

Analysis of responses to the first question revealed that $64 \%$ of the juniors and $33 \%$ of the seniors felt that they were not very aware of gender-equity issues before interacting with the gender equity stack and are now more aware of these issues. Twenty-three percent of the juniors and $21 \%$ of the seniors wrote that they were somewhat aware of the issues before viewing the stack and that their ideas had only changed slightly. And, $10 \%$ of the juniors and $33 \%$ of the seniors said their thinking about gender issues had not changed after interacting with the stack. However, half of these seniors also said that they learned more about gender issues or developed their ideas about gender issues more thoroughly as a result of interacting with the hypermedia presentation. Several seniors wrote comments such as the following:

I am more aware of my interactions within the classroom. This stack made me more aware and also gave me things that I could actually do to improve gender equity in my classroom.

I do not believe it changed my thinking much at all, but I became more aware of some issues. For instance, some of the information provided I had not read before. Although, when given time to reflect, I realized I had witnessed it in classrooms as a student and an intern.

I have always been aware of gender equity in my classroom. The stack did not change my thinking, but supported it.

I am more aware of the differences teachers, textbooks, and society place on boys and girls. I will make more of an effort now to consciously teach gender-equity concepts and to reach and respond equally to boys and girls.

Responses to the second question regarding information from the HyperStudio stack that will be used in their classrooms were especially salient for pre- 
service teachers in this study. Both juniors and seniors ranked Incorporate Role Models and Interact Equally With Boys and Girls as their top choices. The other information that they said they will use in their classrooms included: Display More Pictures of Women; Call on Boys and Girls Equally; Use Gender-Sensitive Language; Provide a Variety of Books; Research Women in Math, Science, and Technology; Vary Teaching Styles for Boys and Girls; Build Self-Esteem in Boys and Girls; and Encourage Nonstereotypical Roles.

\section{DISCUSSION}

The fact that there were no significant differences between the juniors and seniors who participated in this study with regard to their level of awareness about gender-equity issues following exposure to this hypermedia stack is an important finding. Even though the seniors had more exposure to gender issues before this intervention (in the form of about $10 \mathrm{hrs}$ of readings, a video, and group discussions) it appears that even a very brief introduction to genderequity issues using the HyperStudio stack allowed the juniors to feel that they were as aware of these equity issues as the more experienced seniors.

The fact that the juniors were more interested in gender-equity issues than the seniors at the start of the study is also an interesting finding. Perhaps the greater interest on the part of juniors can be attributed to the fact that they had little formal study of gender-equity issues and were anxious to learn how this issue might affect their teaching. Perhaps the seniors thought that equity was not as pressing as other pedagogical issues like classroom management, given that they were in the midst of their student-teaching semester during this study. Or, perhaps the seniors already felt aware enough of gender issues based on prior exposure and earlier opportunities to address inequities in their classrooms.

The fact that there were significant differences between the seniors' level of interest in gender equity from the pretest to the posttest is also intriguing because it implies that, despite the level of a priori awareness and interest in gender-equity issues, the HyperStudio stack was an effective tool in generating added interest in gender equity.

In summary, the juniors' understanding of gender equity changed more dramatically than did the seniors' during this study. This is probably because of the juniors' lack of prior exposure to the formal study of gender-equity issues in the elementary classroom. We also interpret the significant and positive change in the card-sorting activity results as evidence of the efficacy of the HyperStudio stack in changing awareness of, interest in, attitudes toward, and knowledge of gender-equity issues. Of course, it is possible that exposure to ideas about gender-equity issues from taking the pretest and completing the card-sorting activity also impacted participants' attitudes and interest levels and even provided some knowledge for the juniors. However, qualitative analysis of the written responses to the scenarios in the stacks indicated to us that participants actually learned as they progressed through the stack. For example, we found evidence that participants used the background information and strategies found on early cards to respond to scenarios in later cards. 


\section{CONCLUSIONS}

The hypermedia program on gender-equity issues described in this article provided preservice teachers with background information and strategies about gender-equity issues in the elementary school classroom, thus fulfilling a need in the teacher education curriculum for (a) research-based information in this area, (b) an easy-to-use intervention (Rose \& Dunne, 1989), and (c) brief but focused training designed to reduce gender bias in classrooms (Sadker \& Sadker, 1986). Whether teacher educators use this program in a demonstration and discussion mode with the whole class or assign this program as we did to individuals to work through independently, the program provides an excellent basis for further exploration of gender-equity issues in classrooms. As evidenced by both the quantitative and qualitative data from this study, this hypermedia learning environment influenced preservice teachers' thinking about gender-equity issues. The interactive nature of the hypermedia environment provided many opportunities for teachers to think about, write about, and discuss their understanding of gender-equity issues in elementary classrooms.

In conclusion, this study provides both qualitative and quantitative evidence that a hypermedia learning environment positively impacted 51 preservice teachers' awareness of, interest in, attitudes toward, and knowledge of gender-equity issues. Even a one-time intervention in the form of an hour-long exposure to gender-equity issues presented through an interactive hypermedia environment can significantly enlighten preservice teachers about an issue of critical importance in educational settings. Further study of how this program might be useful in educating inservice teachers about gender-equity issues remains to be undertaken, and additional stacks using a similar interactive hypermedia format remain to be developed around other issues in the teacher education curriculum such as special needs students and multicultural education. Furthermore, studies also need to be conducted on the effects of a similar hypermedia program designed for upper elementary school students on gender-equity issues and on the aspects of this stack that were most influential in impacting preservice teachers' awareness of, interest in, and knowledge and attitudes about gender equity.

\section{Contributors}

Dr. Barbara Levin is an assistant professor in the Department of Curriculum and Instruction at the University of North Carolina at Greensboro. Her teaching interests include technology education and social studies methods for preservice teachers. Her research interests include the longitudinal development of teachers' thinking, cases, and case-based pedagogy. Dr. Levin received her $\mathrm{PhD}$ from the Graduate School of Education at the University of California at Berkeley following 17 years experience as an elementary school teacher. Dr. Catherine E. Matthews is an assistant professor in the Department of Curriculum and Instruction at the University of North Carolina at Greensboro, with a specialty in $\mathrm{K}-12$ science education. Her research interests include attitudes and 
achievement in science education, gender and multicultural issues in science education, and environmental education. Dr. Matthews' received her $\mathrm{PhD}$ from the University of Kansas in science education. (Address: Dr. Barbara B. Levin, 345 Curry Building, UNCG, Greensboro, NC 27412; levinb@ dewey.uncg.edu.)

\section{References}

American Association of University Women. (1992). How schools shortchange girls: A study of major findings on girls and education. Washington, DC: Author.

Bransford, J. D., Sherwood, R. D., Haselbring, T. S., Kinzer, C. K., \& Williams, S. M. (1990). Anchored instruction: Why we need it and how technology can help. In D. Nix \& R. Spiro (Eds.), Cognition, education, and hypermedia (pp. 115-141). Hillsdale, NJ: Lawrence Erlbaum.

Clark, R. E. (1983). Reconsidering research on learning from media. Review of Educational Research, 53, 445-459.

Clark, R. E. (1985). Confounding in educational computing research. Journal of Educational Computing Research, 1, 137-148.

Clark, R. E. (1994). Media will never influence learning. Educational Technology Research \& Development, 42(2), 7-19.

Failing at Fairness. (1992). New York: CBS News Educational Enterprise.

Frazier, N., \& Sadker, M. (1973). Sexism in school and society. New York: Harper Row.

Glasser, B. G., \& Strauss, A. L. (1967). The discovery of grounded theory. New York: Aldine deGruyter.

Jacobson, M. J., \& Spiro, R. J. (1995). Hypertext learning environments, cognitive flexibility, and the transfer of complex knowledge: An empirical investigation. Journal of Educational Computing Research, 12, 301-333.

Kozma, R. B. (1991). Learning with media. Review of Educational Research, 61, 179-212.

Leach, L. (1994). Sexism in the classroom: A self-quiz for teachers. Science Scope, 17(6), 54-59.

Miles, M. B., \& Huberman, A. M. (1984). Qualitative data analysis: A sourcebook of new methods. Beverly Hills: Sage Publications.

Nelson, W. A., \& Palumbo, D. B. (1992). Learning, instruction, and hypermedia. Educational Multimedia and Hypermedia, 1, 287-299.

Rose, T., \& Dunne, F. (1989). Gender equity for a new generation: Teacher educators can make a difference. Contemporary Education, 6(i), 29-31.

Sadker, M., \& Sadker, D. (1985, March). Sexism in the schoolroom of the 80s. Psychology Today, 19, 54-57.

Sadker, M., \& Sadker, D. (1986, March). Sexism in the classroom: From grade school to graduate school. Phi Delta Kappan, 67, 512-515.

Sadker, M., \& Sadker, D. (1994). Failing at fairness: How America's schools cheat girls. New York: Scribner.

Sadker, M., Sadker, D., \& Klein, S. (1991). The issue of gender in elementary and secondary education. Review of Educational Research, 17, 269-334. 
Sadker, M., Sadker, D., \& Steindam, S. (1989, March). Gender equity and educational reform. Educational Leadership, 46, 44-47.

Sanders, J. (1995). Teacher education equity project. Unpublished manuscript, City University of New York.

Spiro, R. J., \& Jehng, J. C. (1990). Cognitive flexibility theory and hypertext: Theory and technology for the nonlinear and multidimensional transversal of complex subject matter. In D. Nix and R. Spiro (Eds.), Cognition, education, and hypermedia. (pp. 163-205). Hillsdale, NJ: Lawrence Erlbaum.

Zachary, G. P. (1994, March 18). High-tech culture still impedes women. Wall Street Journal, B1-B2. 